\title{
TITLE:
}

\section{In-Situ Ground Surveying by the NSWS Testing Machine}

$\operatorname{AUTHOR}(\mathrm{S})$ :

Inazumi, Shinya; Okita, Kozo; Kondo, Takumi; Kazarashi, Kenji

\section{CITATION:}

Inazumi, Shinya ...[et al]. In-Situ Ground Surveying by the NSWS Testing Machine. International Journal of GEOMATE 2011, 1(1): 1-9

\section{ISSUE DATE:}

2011-10

URL:

http://hdl.handle.net/2433/152406

\section{RIGHT:}

Copyright (c) 2011, International Journal of GEOMATE. All rights reserved, including the making of copies unless permission is obtained from the copyright proprietors. Pertinent discussion including authors' closure, if any, will be published in the Oct. 2012 if the discussion is received by April 2012. 
Int. J. of GEOMATE , Oct. 2011, Vol. 1, No.1 (Sl. No. 1), pp. 1-9

Geotec., Const. Mat. and Env., ISSN:2186-2982(P), 2186-2990(O), Japan

\title{
In-Situ Ground Surveying by the NSWS Testing Machine
}

\author{
Shinya Inazumi, Graduate School of Engineering, Kyoto University \\ Kozo Okita, Okita-ko Co., Ltd. \\ Takumi Kondo, K\&O Corporation \\ Kenji Kazarashi, Nippon Geophysical Prospecting Co., Ltd.
}

\begin{abstract}
This paper outlines the development of the NSWS (Nippon Screw Weight System) testing machine. In compliance with the Swedish sounding (SWS) test that determines loading and rotational penetration resistance. The NSWS was developed as an in-situ ground surveying device to detect super soft zones in the ground, including hollows and loosening, in detail, by allowing operation in the 0 to $2500 \mathrm{~N}$ load range, with very close measurements intervals and penetration speed control, the features of which cannot be achieved by the SWS testing machine. Additionally, findings from an in-situ surveying of in-ground hollows identified using the NSWS testing machine are reported in this paper. The machine achieved a conversion $\mathrm{N}$-value measuring intervals of $2.5 \mathrm{~cm}$ (or $3.8 \mathrm{~cm}$ ), determination of ranges of hollow and loosening zones through pre-setting of penetration speed, and detection of super soft zones of conversion $\mathrm{N}$-values 1 and below with a load range of 0 to $1000 \mathrm{~N}$.
\end{abstract}

Keywords: NSWS testing machine, in-ground hollow, in-ground loosening zone, conversion $\mathrm{N}$-values

\section{INTRODUCTION}

With intense postwar grooming, social capital that supports the development of the country and ensures the safety of its citizens is now a manifestation of the 21 century. Most of the immediate post war structures are now on the ageing threshold of 50 years. Meanwhile, related technology is also moving from construction to maintenance, and it is now important to utilize the limited resources effectively; at the same time, "restoration" and "assessment" of social capital has become important for the continuation of its fundamental functionalities.

For example, although there are some direct factors such as ocean waves, flooding, etc. that cause the destruction of coastal revetment walls, one of the main reasons behind the destruction of only a particular zone of a continuous shore can be the presence of hollows and loosening zones in the back side zone of the shore ground. Generally, hollows and loosening zones develop invisibly in the ground over time due to continuous ocean waves or the flowing waters of the ocean or river, and also due to sediment discharge caused by high tidal waves, abnormal flooding, or the presence of underground water. Considering that the development of hollows and loosening zones in the ground is a disintegrative process for the in-ground structure such as a sea bank, sea shore, roads, etc., then an in-ground testing machine to investigate and evaluate that process is absolutely necessary as a technology for "restoration" of the in-ground structures.
Further, a ground surveying technology that targets "restoration" of in-ground structures strongly demands an efficient or economically efficient in-situ testing method with promptness of result or continuity of data and which can evaluate the conditions of the ground more accurately [1], [2].

The Swedish sounding (SWS) test is an in-situ ground surveying method that determines penetration resistance value $\left(\mathrm{N}_{\mathrm{sw}}\right)$ by rotations with the lowest load $\left(\mathrm{W}_{\mathrm{sw}}\right)$ required for penetration and the $1000 \mathrm{~N}$ static load [3]. Basically, it is developed for investigating the bearing capacity of roadbeds. However, it has been used in many instances of coastline surveying; since there are fewer constraints about the ground in static sounding, measurements upto $15 \mathrm{~m}$ are possible, with the added advantage that the testing machine can also be disassembled to a portable size. However, the measurement intervals in the SWS test is a high $25 \mathrm{~cm}$.

In this case, while considering the bank water leakage, which is one of the reasons for flooding, it is necessary to locally identify the leakage points and their size and locations and to grasp the status of sediment discharge of the ground. In such instances, it is necessary to define boundaries for 3 different geological strata i.e. of gas, liquid and solid phases; at the same time it is important to identify super soft zones in the ground including hollows and loosening, which should be measured at intervals of $5 \mathrm{~cm}$ or with an indicator for determining their condition is necessary. These requirements form the basis of the development of the NSWS (Nippon Screw Weight System) testing machine (see Fig. 1). In compliance with the SWS test and detects in detail, by hydraulic and pneumatic control of loading and with very closely spaced measurement capability [4]-[6]

This paper outlines the development of the NSWS testing machine (see Fig. 1). In compliance with the conventional SWS test, the NSWS determines loading and rotational penetration resistance. The NSWS was developed as an in-situ ground surveying device to detect in detail, super soft zones in the ground including hollows and loosening by allowing operation in the 0 to $2500 \mathrm{~N}$ load range, very frequent measuring intervals and penetration speed control, the features of which cannot be achieved by the SWS testing machine. Findings from an in-situ surveying of in-ground hollows using the NSWS testing machine are also reported in this paper. 


\section{OVERVIEW OF NSWS TESTING MACHINE}

\subsection{Development and Characteristics of NSWS Testing Machine}

Notwithstanding the fact that the SWS testing machine is easily portable, testing time is short, the testing methods are simple and the cost of testing is affordable compared to other mechanical boring methods, it cannot be applied on dense sandy ground layer, gravel, or rocky ground layer [6]. Also, the measuring intervals in the conventional standard penetration test or SWS test are too large to identify the different soil structures, stratum barriers or locations of bleeding channels, existence of hollow ground and loosening in the surrounding soil, etc. Measurements should ideally be possible at intervals of $5 \mathrm{~cm}$ or less.

In light of these shortcomings, the NSWS in-situ ground surveying device that can identify super soft zones in the ground has been developed. It is equipped with hydraulic and pneumatic control systems of loading as well as a closely spaced measuring intervals unit analogous to that the SWS testing machine [4]-[6]. There are two types of NSWS testing machines, namely; model 1200 (with a maximum load $1200 \mathrm{~N}$ and measuring intervals of $2.5 \mathrm{~cm}$ ) which has been developed for measurement of super soft zones and, model 2500 (with a maximum load $2500 \mathrm{~N}$ and measuring intervals of $3.8 \mathrm{~cm}$ ) that enables penetration in gravelly or rocky ground layers.

The NSWS testing machine has the following characteristics:

(1) Lightweight and compact (total weight 70 to $75 \mathrm{~kg}$, total length $\times$ total width $\times$ total height $=70$ to $75 \times 50 \times$ $250 \mathrm{~cm})$; easily portable.

(2) It can control the load continuously from 0 to $1200 \mathrm{~N}$ or from 0 to $2500 \mathrm{~N}$ by using a loading system equipped with hydraulic and pneumatic controls.
(3) Significantly enhanced resolution to measure super soft zones, right from zero, depending on the load magnitude.

(4) Internal structure of the ground can be interpreted in detail, almost continuously by measuring the load, penetration depth and the number of rotations at $2.5 \mathrm{~cm}$ or $3.8 \mathrm{~cm}$ intervals.

(5) Simultaneously measure penetration time while loading, and can detect ground self-subsidence (hollow and loosening) zone in the ground from the penetration speed.

(6) It can measure the direction of tilt on the surface and the slope on the ground.

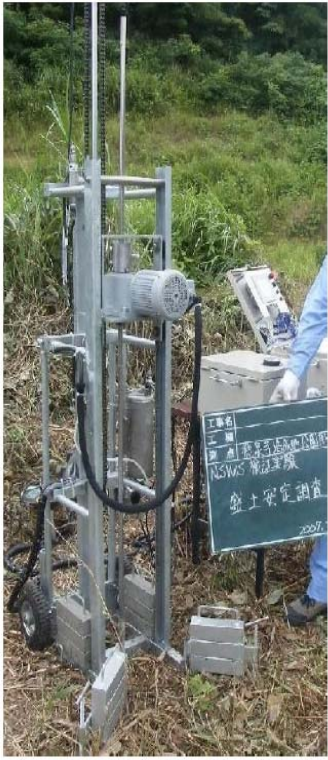

Figure 1. Hardware components of NSWS (Nippon Screw Weight System) testing machine

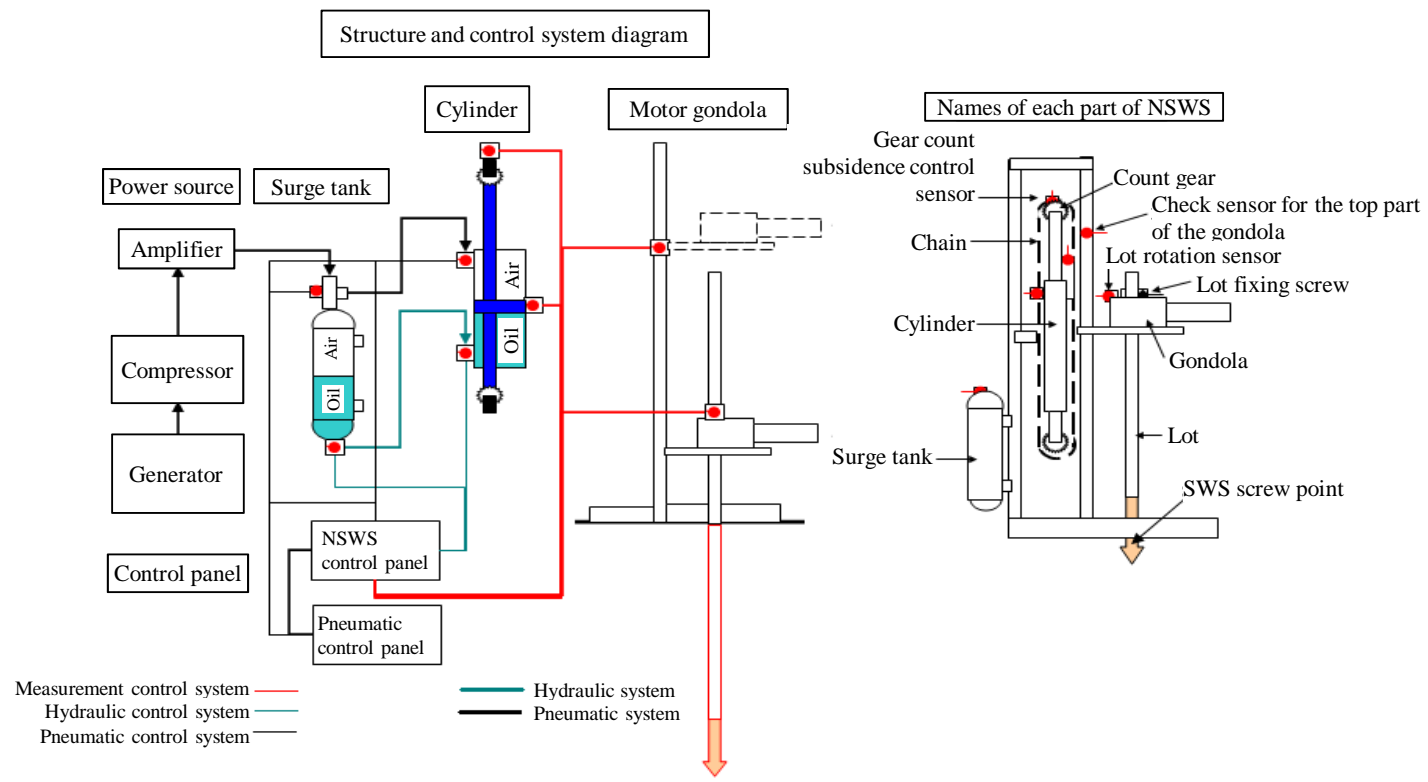

Figure 2. NSWS structure and loading features (components) 
(7) It can identify in-situ, the hollow or loosening zone.

\subsection{Functionalities of NSWS Testing Machine}

(1) Amount of load

Although the loading component of the SWS testing equipment is automatic and widely used because of its efficiency, it has some limitations in terms of the load resolution which is fixed at a minimum of $500 \mathrm{~N}$.

As shown in Fig. 2, for the self-weight of motor + gondola, the 2 cylinders for hydraulic and pneumatic control, the load is applied in the opposite direction to produce a zero load condition, where successive load measurements from 0 to $2500 \mathrm{~N}$ are made possible as opposed to the SWS testing machine. Further, accuracy of the load is maintained by consistent calibration using a calibration device.

\section{(2) Measuring intervals}

The gondola in the NSWS testing machine is structured as a moving pulley using gears that are fixed to the cylinder and chains that are suspended. A chain feed length of twice that of the moving distance of the cylinder (chain pitch $=$ gear pitch, $1.25 \times 2=2.5 \mathrm{~cm}$ or $1.9 \times 2=3.8 \mathrm{~cm}$ ) is sensed through a sensor, and this length is used as a measuring unit. In contrast to the conventional SWS test with measurement intervals of $25 \mathrm{~cm}$, detailed data can be acquired using the NSWS testing machine. Also, by using the measurement control time for very closely spaced measuring intervals, the time required for penetration can be defined beforehand and detection of scuttle conditions or super soft zones like hollow and loosening zones can be possible.

\section{(3) Inclination measurement}

Since the load control of the NSWS testing machine is composite of hydraulic and pneumatic control systems, the load can be applied irrespective of the direction of load action, thereby making the measurements of inclined areas possible (see Fig. 3). Due to this, as shown in Fig. 4, the range of the hollow or extremely loose soil (loosening zone) can be determined.

\section{(4) Identifying in-ground hollows and loosening zones}

The NSWS testing machine controls the rotations and the load strictly with penetration time in the measuring intervals as a parameter that identifies the hollow and loosening zones. An example of a measurement result of the NSWS testing machine, along with interpretative explanations, is provided in Fig. 5. In this case, the time for measurement data transfer and penetration required for the measuring unit interval $(2.5 \mathrm{~cm})$ are processed through a computer. If the value is more than or equal to the preset penetration time (settlement time) of 0.5 second (variable), rotation or loading is stopped and the measurements are re-started by resetting the load to zero. The in-ground hollow and loosening zones are then identified by comparing actual load status with the detection accuracy relative to the "set penetration time" or "continuation of that time". A total of 4 abnormal zones with depth 0.75 to $1.5 \mathrm{~m}$ are detected as shown in Fig. 5; it can therefore be inferred that there are hollow and loosening zones within that area.

Since a hollow rod is used in the NSWS testing machine

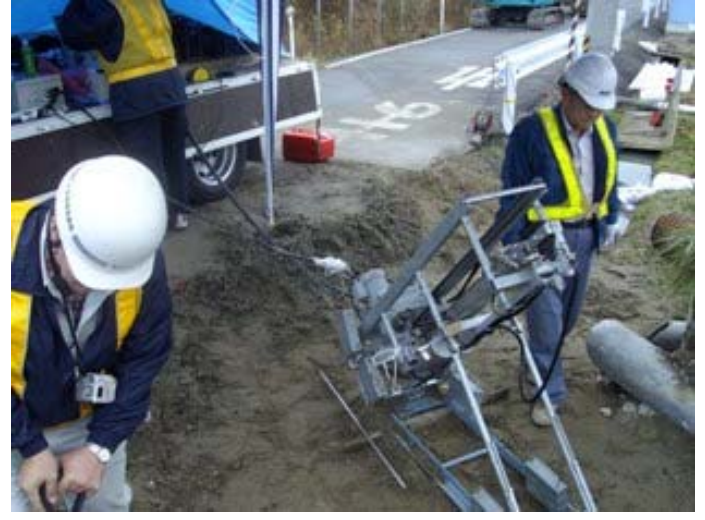

Figure 3. Appearance of inclination measurement with NSWS testing machine
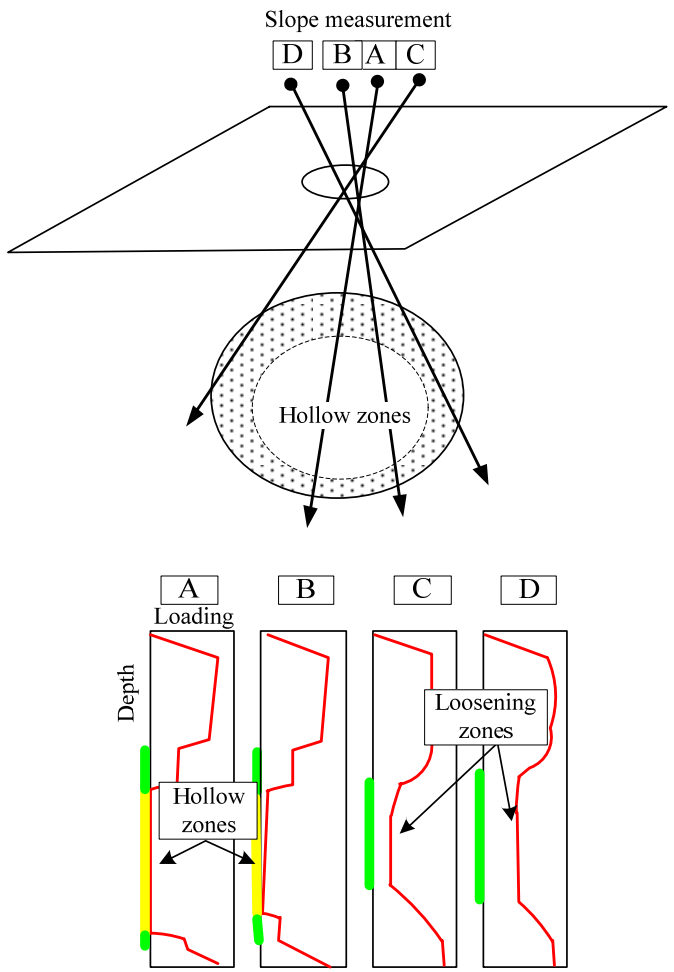

Figure 4. Concept of detection for hollow or loosening zone in ground

while identifying the in-ground hollow and loosening zones, it can be fitted with devices like a camera or a water gauge to allow visualization of the in-ground hollows or to figure out the existence of water etc. in the hollows. Additionally, pressure relief control type high-viscosity pumps are used incrementally in the NSWS testing machines. Identified in-ground hollows and loosening can be repaired simply by injecting cement, water-swelling material, etc. [5]. 


\section{IN-GROUND HOLLOW SURVEYING USING NSWS TESTING MACHINE}

\subsection{Overview of Ground Surveying Site}

Before restoring water flow in the sewer pipe, in-ground hollow around the particular sewer pipe located at approximately $6.5 \mathrm{~m}$ below the ground surface was investigated using the NSWS testing machine (model 1200; maximum amount of load $1200 \mathrm{~N}$; measuring intervals $2.5 \mathrm{~cm})$.

There are two methods for investigating the soil condition of the area where hollows etc. are expected to develop under the ground surface. The first is a direct method, like test drill investigation, boring (Standard penetration testing), and SWS testing; the other is an indirect method such as underground radar exploration and elastic wave tomography exploration. The hollow expected under that site is above the sewer pipe $(\phi 1000 \mathrm{~mm})$ and spread deep around the $6 \mathrm{~m}$. Further, geological conditions at the site can be identified (see Fig. 6) from the conventional boring test result. The result shows that the groundwater level is high and there is loose sandy soil and extremely soft cohesive soil with $\mathrm{N}$-value $=0$ to 6 . That makes it difficult to detect the in-ground hollows even after geological explorations like underground radar exploration, high density surface wave exploration, shallow seismic reflections and high density electric wave exploration. Also, it is difficult to grasp the minute soil conditions of soft ground even after pilot boring.

\subsection{Steps for In-Situ Ground Surveying}

The abbreviated procedure for in-situ ground surveying aimed at identifying the soil conditions of the upper side of the sewer pipe in the water flow shown in Fig. 7, is as follows.

(1) Carry out in-ground hollow surveying after removing the sewer pipe in the water flow $(\phi 350 \mathrm{~mm})$.

(2) Adjust the sequential direction and the angle of every test hole 1) to 3), execute the test in the direction towards the top surface and horizontal direction of the sewer pipe in the water flow line and identify the soil condition focusing on the top surface of damaged places of the sewer pipe in the water flow (as shown in Fig. 7).

(3) Based on the result of test holes 1) to 3), perform testing at further test holes 4) to 6) and identify the soil condition from the vertical and horizontal directions of the top surface (as shown in Fig. 7).

\subsection{Details of Test Holes}

This is a case where the upper elevation of the sewer pipe in the water flow under the site is approximately $\mathrm{H}=-6.0 \mathrm{~m}$, and depth of each test hole is below this elevation. Table 1 shows the details of each test hole.

Tested hole 1) a $45^{\circ}$ downward position to the normal direction (northerly direction) from a position close to the pillar location. Hole length is $7.4 \mathrm{~m}$ and test depth is $5.2 \mathrm{~m}(\mathrm{H}$ $=-6.0 \mathrm{~m})$.

Tested hole 2) a $45^{\circ}$ downward position from a position close

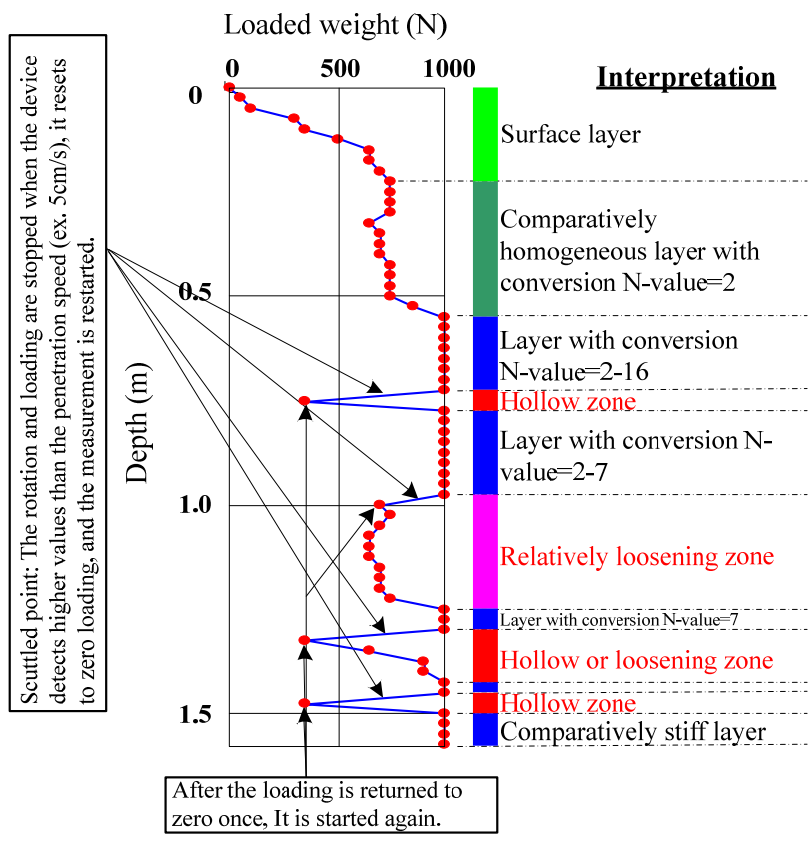

Figure 5. An example of result and interpretation of measurement with NSWS testing machine

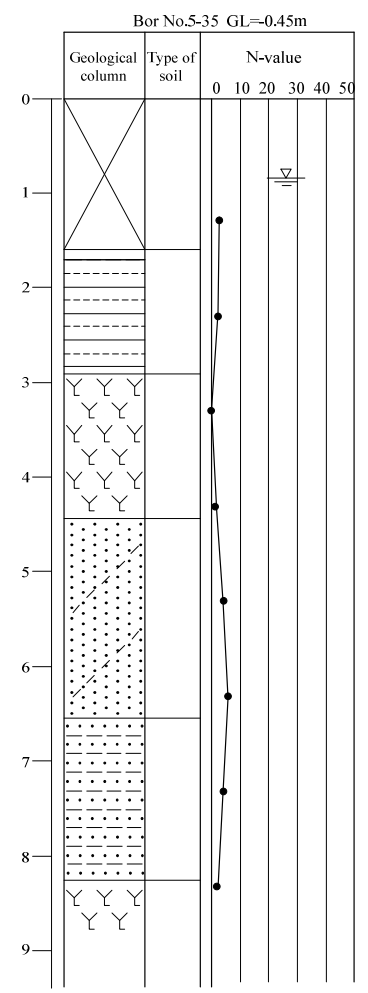

Figure 6. Geological conditions within vicinity of investigation ground measured from existing boring test

to the pillar location, about $45^{\circ}$ to the south from sewer pipe direction. Hole length is $8.2 \mathrm{~m}$ and test depth is $5.8 \mathrm{~m}(\mathrm{H}=$ $-6.6 \mathrm{~m})$

Test hole 3) a $45^{\circ}$ downward position from a position close to 
the pillar location, about $135^{\circ}$ to the south from sewer pipe direction. Hole length is $8.07 \mathrm{~m}$ and test depth is $5.7 \mathrm{~m}(\mathrm{H}=$ $-6.5 \mathrm{~m})$

Using test holes 1) to 3), tested a fan-like shape of $135^{\circ}$ at the south in normal direction from the sewer pipe. Additionally, after finishing test holes 1) to 3), Fig. 8 shows that the entire soil near the border of the embankment around the pillar position and cohesive soil is soft; however, even though the soil conditions are almost similar to the conventional pilot boring result (see Fig. 6), no results could be obtained indicating any significant hollow. Therefore, testing of places far from the pillar position is carried out in the vertical direction as test holes 4 ) to 5) in order to determine whether the soil condition there is soft similar to test holes 1) to 3).

In test holes 1) to 5), it was found that the soil condition was entirely soft, but since there was no indication of a significant hollow, it was assumed that the extent of hollow is not much and therefore tested one place immediately near the pillar position as test hole 6).

\subsection{Test Result (Conversion N-value)}

Using the Inada method [7], a test result is obtained from the number of half rotations $\left(\mathrm{N}_{\mathrm{sw}}\right)$ and amount of load $\left(\mathrm{W}_{\mathrm{sw}}\right)$, and the result is taken as a conversion $\mathrm{N}$-value in every depth and the result of every test position is shown in Figs. 9, 10, 11, 12, 13 and 14. Here, from the report in the Okita et al. (2010), it is clear that the NSWS test and SWS test for conversion $\mathrm{N}$-value by the Inada method indicated in Tamura et al. (2004) have high correlation.

In test hole 1), except for the embankment, the depth curve of conversion $\mathrm{N}$-value increased gradually from 2.5 to 5.0 and no decline was observed in the middle. Therefore, no hollows or loosening were found in test hole 1) (see Fig. 9). In test hole 2), except for the embankment, the depth curve of conversion $\mathrm{N}$-value changed gradually from 2.0 to 5.0 and even though there were some abnormal values in between due to the presence of stones, no major declines were observed. Therefore, no hollows or loosening were found in test hole 2) (see Fig. 10).

In test hole 3), except for the embankment, the depth curve of conversion $\mathrm{N}$-value changed gradually from 2.0 to 5.0 and even though there were some abnormal values in between due to the presence of stones, no major declines were observed. Therefore, no hollows or loosening were found in test hole 3) (see Fig. 11).

In test hole 4), except for the embankment, the depth curve of conversion N-value changed gradually from 2.5 to 5.0 and even though there were some abnormal values in between due to the presence of stones, no major declines were observed. Therefore, no hollows or loosening because of existence of hollows were found in test hole 4) (see Fig. 12). In test hole 5), except for the embankment, the depth curve of conversion $\mathrm{N}$-value changed gradually from 2.5 to 5.0 and even though there were some abnormal values in between due to the presence of stones, no major declines or changes were observed. No hollows or loosening were found in test

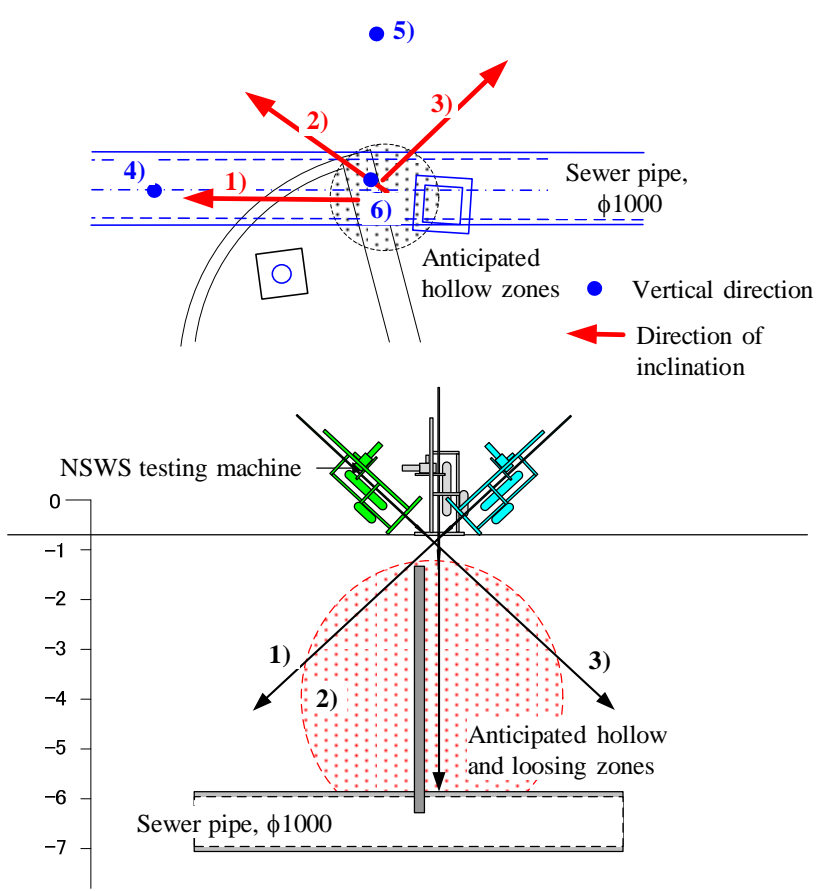

Figure 7. Outline of implementation plan for in-situ ground surveying using NSWS testing machine

Table 1. Details of each test hole

\begin{tabular}{c|c|c|c|c}
\hline $\begin{array}{c}\text { Test } \\
\text { hole }\end{array}$ & $\begin{array}{c}\text { Ground } \\
\text { elevation } \\
(\mathrm{m})\end{array}$ & $\begin{array}{c}\text { Inclined } \\
\text { angle } \\
\text { (degrees) }\end{array}$ & $\begin{array}{c}\text { Extension } \\
(\mathrm{m})\end{array}$ & $\begin{array}{c}\text { Altitude in } \\
\text { test point (m) }\end{array}$ \\
\hline 1$)$ & -0.75 & 45 & 7.40 & -5.98 \\
\hline 2$)$ & -0.75 & 45 & 8.20 & -6.55 \\
\hline 3$)$ & -0.75 & 45 & 8.07 & -6.46 \\
\hline 4$)$ & -0.48 & 90 & 4.98 & -5.46 \\
\hline 5$)$ & -0.42 & 90 & 5.98 & -6.40 \\
\hline 6$)$ & -0.93 & 90 & 5.23 & -6.16 \\
\hline Total & \multicolumn{4}{|c}{ Altitude in upper end of the sewer pipe: $\mathrm{H}=-6.0 \mathrm{~m}$}
\end{tabular}

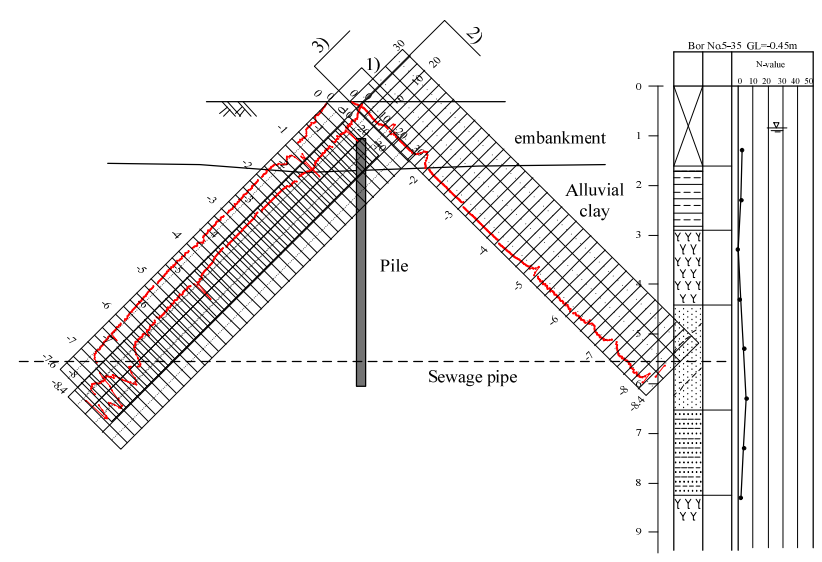

Figure 8. An example of test results measured by NSWS testing machine for test holes 1)-3) 


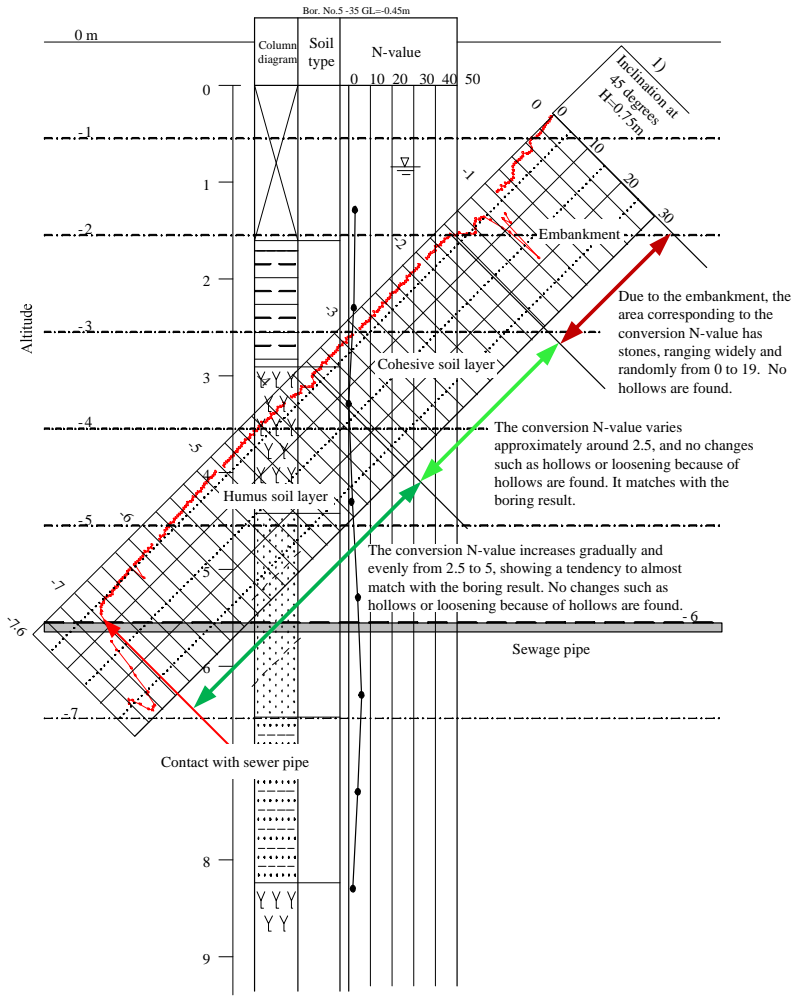

Figure 9. Distribution of conversion N-value toward depth directions in test hole 1)

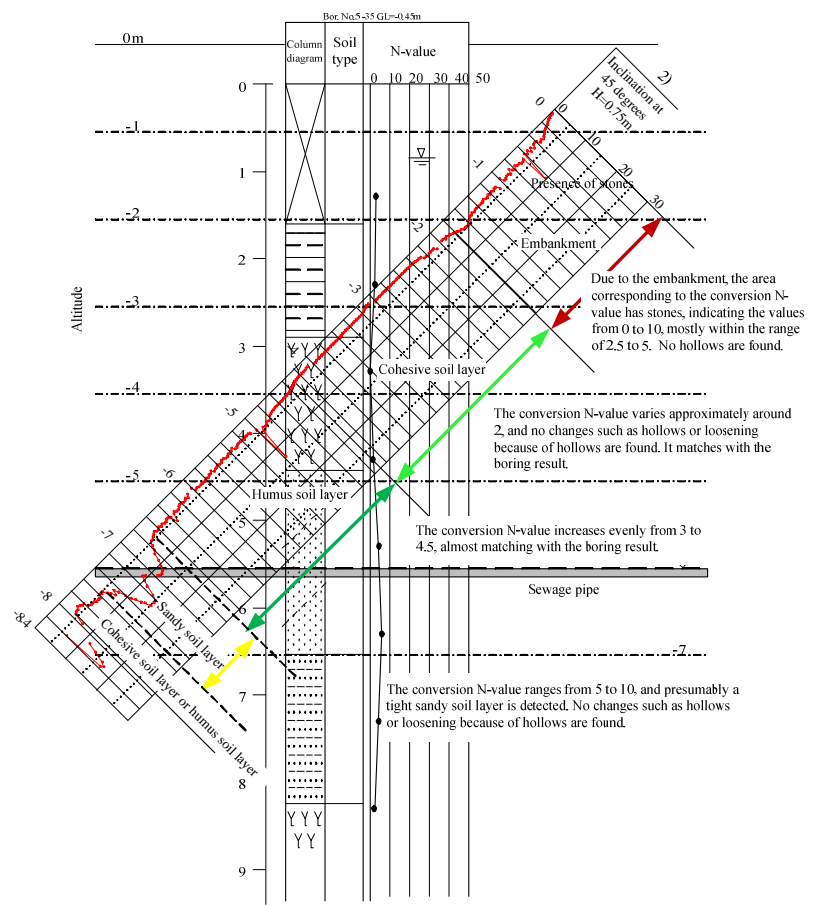

Figure 10. Distribution of conversion N-value toward depth directions in test hole 2)

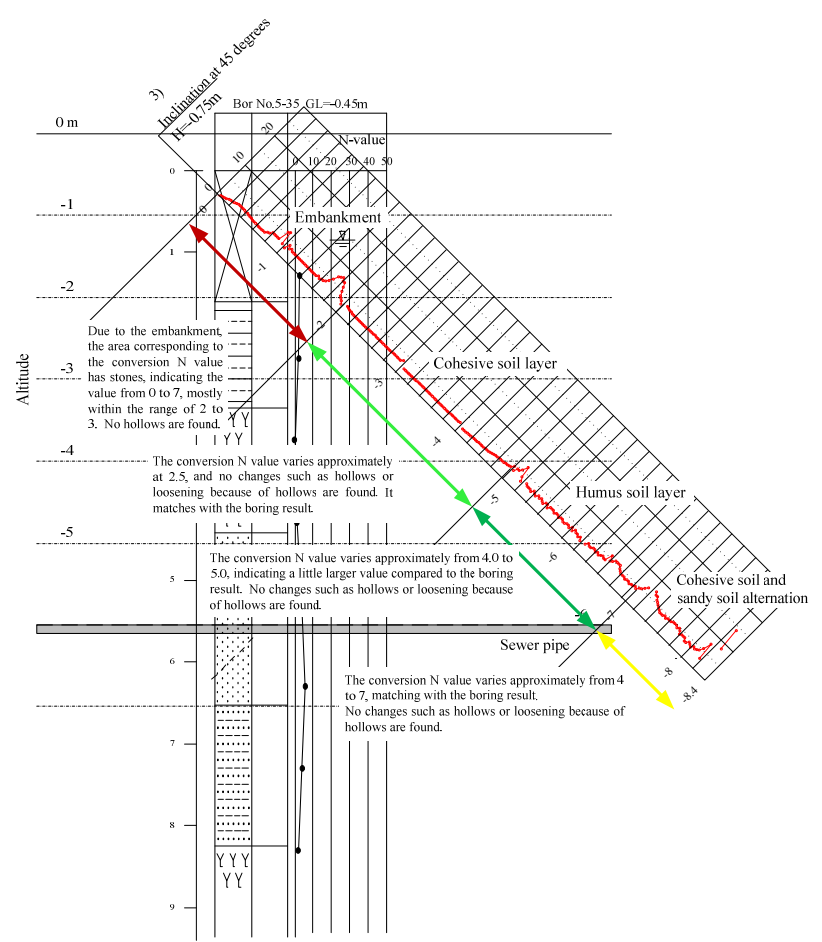

Figure 11. Distribution of conversion N-value toward depth directions in test hole 3)

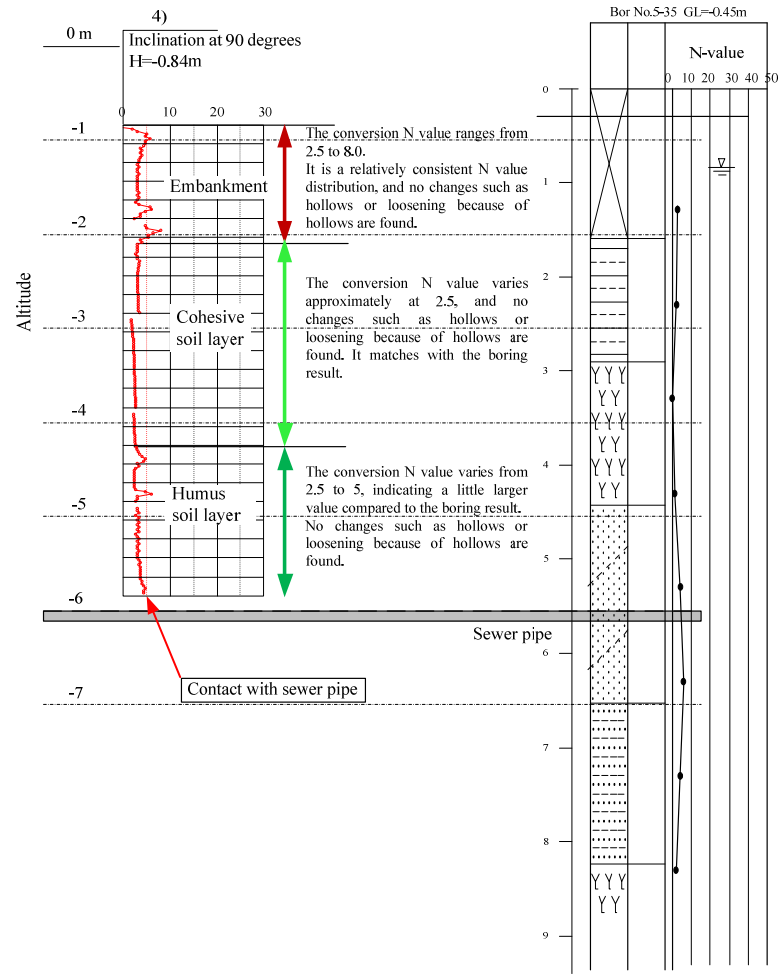

Figure 12. Distribution of conversion N-value toward depth directions in test hole 4) 


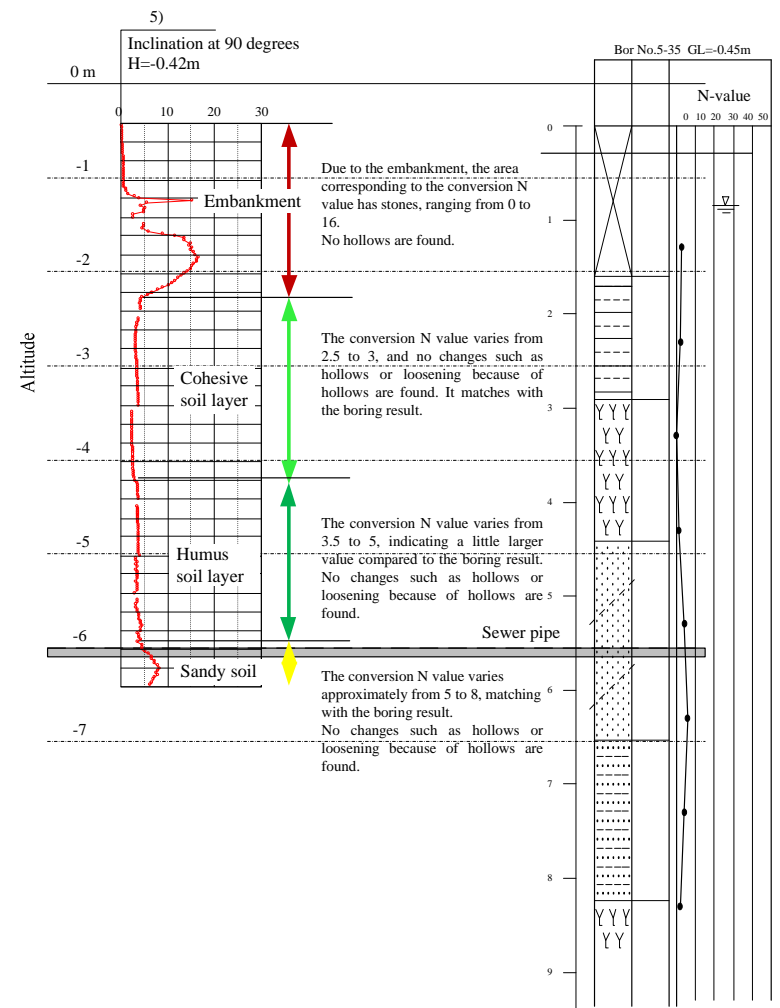

Figure 13. Distribution of conversion $\mathrm{N}$-value toward depth directions in test hole 5)

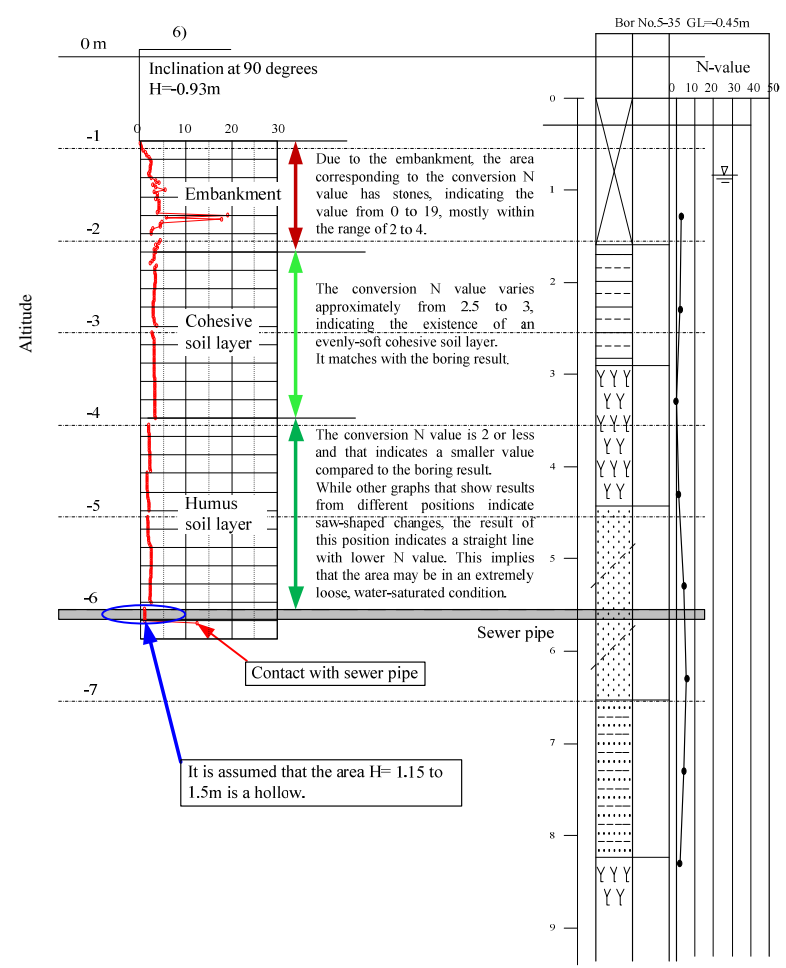

Figure 14. Distribution of conversion N-value toward depth directions in test hole 6) hole 5) including the embankment (see Fig. 13).

Test hole 6 ) is a test executed $0.5 \mathrm{~m}$ away from the pillar position in a vertical direction. The depth curve of conversion $\mathrm{N}$-value, except for the embankment, is uniformly distributed 2.5 to 3.0 up to a depth of around $-4 \mathrm{~m}$ near elevation; compared with the former test holes 1) to 5) at depth of $-4 \mathrm{~m}$ or more, the measurements were 2.5 or less. Also, some variations from test holes 1) to 5), such as decrease in values near $-4.5 \mathrm{~m}$ elevation, were observed. Also, $20 \mathrm{~cm}$ immediately above the sewer pipe, conversion $\mathrm{N}$-value suddenly changes from 2.5 to 1 , which indicates that there is a hollow in this area. Therefore, in test hole 6) which is $0.5 \mathrm{~m}$ away from the pillar position, loosening is caused from the first top $2 \mathrm{~m}$ of the sewer pipe, which indicates a hollow near the sewer pipe (see Fig. 14).

\subsection{Determining an In-Ground Hollow}

Fig. 15 indicates the geological longitudinal diagram depicting the results of test holes 1 ) to 6) onto the center line of the sewer pipe. In test hole 1), extremely soft zones having conversion $\mathrm{N}$-value less than or equal to 2 at the embankment were identified. To determine whether this soft layer had formed due to damage to the sewer pipe, extensive testing was executed focusing on the pillar position. At the site, a range of loose soil types are spread as a result of previous test boring adjacent to the sewer pipe and, therefore, there are chances of hollows spread under the paved surface (see Fig. 6). According to the test result of the area immediately above the damaged zones (test holes 1) to 3)) and the surrounding test holes 4) to 5), no super soft zones indicating the presence of hollows, were detected. Thus, it can be concluded that the area up to $6 \mathrm{~m}$ deep from the pipe is uniformly distributed of very soft sandy soil and humus soil with conversion $\mathrm{N}$-value from 2.5 to 5 , excluding the embankment. On the other hand, in the area near the pillar position (test hole 6)), hollows were detected $20 \mathrm{~cm}$ immediately above the sewer pipe and, unlike the characteristics exhibited within test holes 1) to 5), the area up to $2 \mathrm{~m}$ above the pipe is extremely soft with conversion $\mathrm{N}$-value less than or equal to 2. The range of hollows and loosening in the testing phase is within $2 \mathrm{~m}$ above damaged zones (see Fig. 16) and not under the paved surface.

\section{CONCLUSIONS}

The NSWS testing machine can provide detailed soil information that was previously difficult to gain through conventional in-situ ground surveying methods. It can be an effective surveying tool to establish restoration or disaster prevention techniques for in-ground structures, investigating current problems associated with hollows under river banks, tanks, buried valley embankments, widening of embankments, the seacoast and river structures, investigating road damage caused by underground objects like sewer pipes, etc. Also, in this paper, in-situ surveying of in-ground hollows around a sewer pipe was performed using the NSWS test machine. As a result, hollows and loosening in the 
Int. J. of GEOMATE , Oct. 2011, Vol. 1, No.1 (Sl. No. 1), pp. 1-9

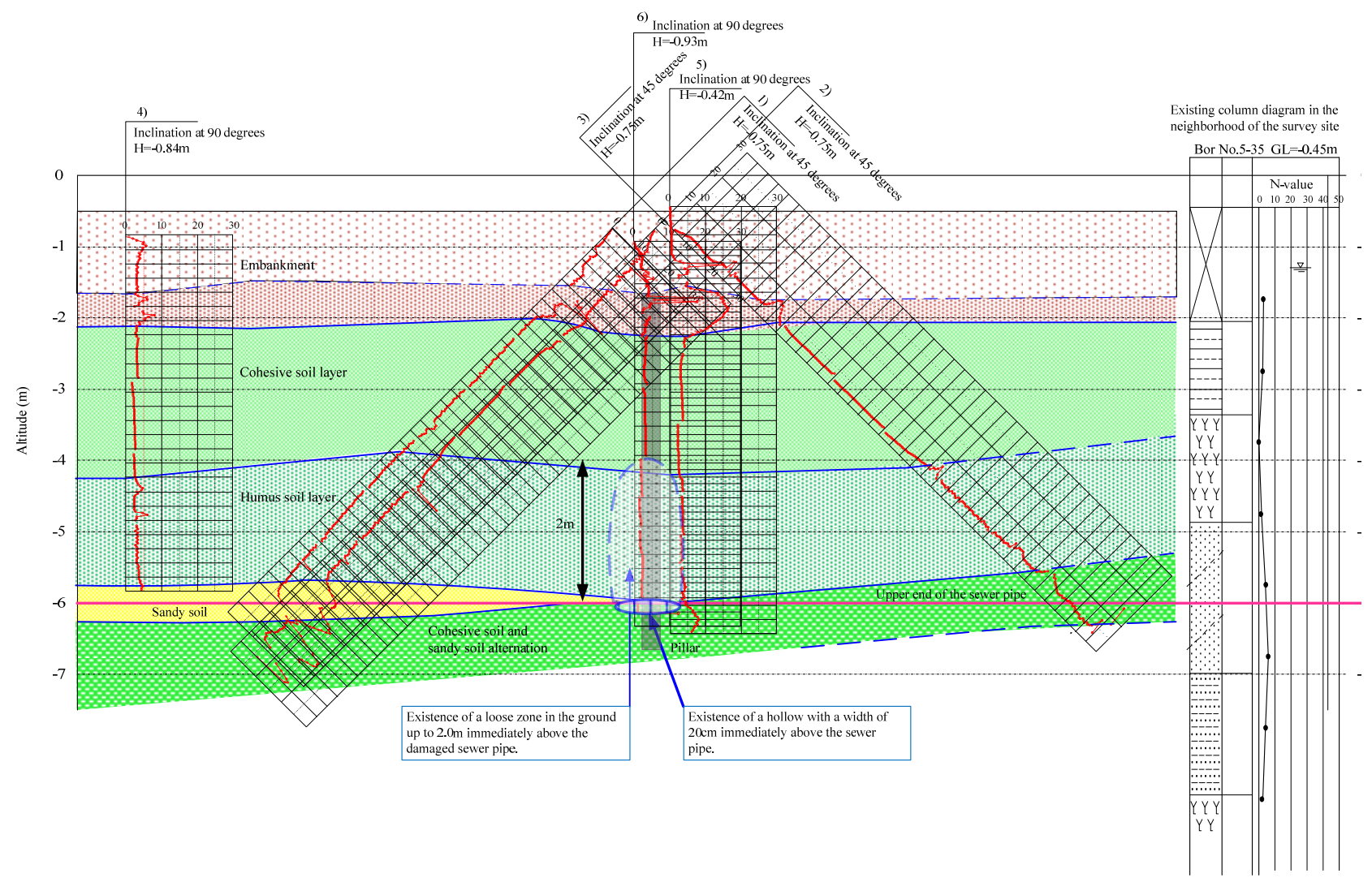

Figure 15. NSWS testing result and geological longitudinal diagram (projecting onto the center line of a sewer pipe)

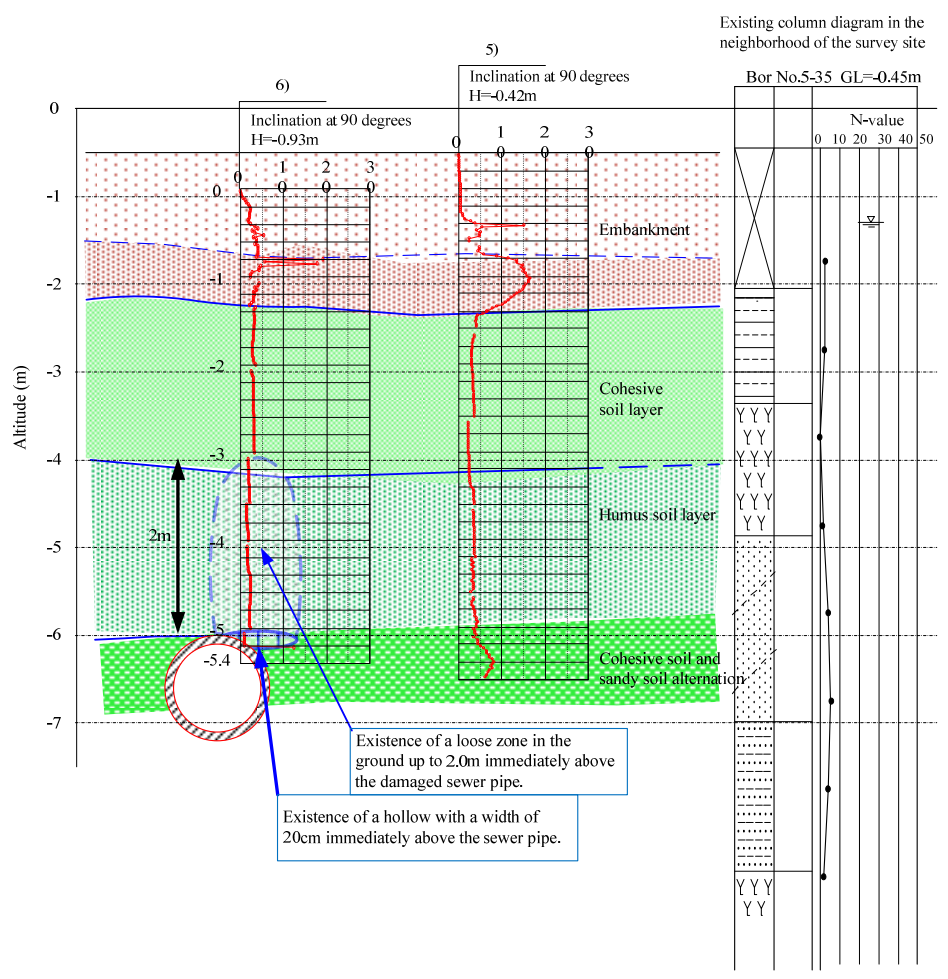

Figure 16. NSWS testing result and geological latitudinal diagram 
ground were identified. This device also allows closely spaced measurements at intervals of $2.5 \mathrm{~cm}$ (or $3.8 \mathrm{~cm}$ ), determination of ranges of hollow and loosening zones through pre-setting of penetration speed, and detection of super soft zones of $\mathrm{N}$-values 1 and below with a load range of 0 to $1000 \mathrm{~N}$.

The NSWS test machine is therefore proposed as a new ground measuring tool with versatile features. It is expected to be applicable in various situations like behavioral changes in the soil such as loosening etc. due to collapse or fall, surveying of boundary specification and extension, and studying various soils ranging from super soft to boulder zones.

\section{REFERENCES}

[1] Lunne T, Robertson PK, Powell JJM, "Cone penetration testing in geotechnical practice,” Blackie Academic \& Professional, 1997, pp.149-151.

[2] Fukue M. "Review of geotechnical and geoenvironmental investigation methods for the last decade (in Japanese)," Tsuchi-to-Kiso, JGS, vol.54, no.4, 2006, pp.1-3.

[3] Dahlberg R, Bergdahl U, "Investigations on the Swedish ram-sounding method," Proc. of the European Symposium on Penetration Testing, 1973, pp.93-102.
[4] Okita K, Takashimizu H, Shinozuka J, Okuno H, "A basic study on evaluation of ground by new swedish weight sounding (NSWS) (in Japanese)," Proc. of the 2010 National Symposium on Environmental and Measuring Technology of Ground, JGS, 2010, pp.145-152.

[5] Inazumi S, Shishido K, Okita K, "Survey and repair for void in ground using NSWS (in Japanese)," Proc. of the 9th National Symposium on Ground Improvement, JSMS, 2010, pp.233-236.

[6] Kondo T, Okita K, "New ground survey of natural subsidence (the cavern is included) area (in Japanese)," Geotechnical Engineering Magazine, JGS, Vol.56, No.9, 2008, pp.30-31.

[7] Tamura M, Kawamura M, Edahiro T, Mizutani Y, Fujii M, Koguchi K, "The present condition and the subject of the foundation investigating method by Swedish weight sounding (in Japanese),” Tsuchi-to-Kiso, Vol.52, No.4, 2004, pp.8-10

International Journal of GEOMATE , Oct. 2011, Vol. 1, No.1 (Sl. No. 1)

MS No. 1a received August 1, 2011, and reviewed under GEOMATE publication policies.

Copyright @ 2011, International Journal of GEOMATE. All rights reserved, including the making of copies unless permission is obtained from the copyright proprietors. Pertinent discussion including authors' closure, if any, will be published in the Oct. 2012 if the discussion is received by April 2012.

Corresponding Author: Shinya Inazumi 